\title{
Cardiac Morphofunctional Characteristics of Transgenic Rats With Overexpression of the Bradykinin B1 Receptor in the Endothelium
}

\author{
R. F. LEVY ${ }^{1}$, A. J. SERRA ${ }^{2}$, E. L. ANTONIO ${ }^{3}$, L. DOS SANTOS ${ }^{4}$, D. S. BOCALINI ${ }^{5}$, \\ J. B. PESQUERO ${ }^{3}$, M. BADER ${ }^{6}$, V. F. MERINO ${ }^{7}$, H. A. DE OLIVEIRA ${ }^{2}$, \\ E. C. DE ARRUDA VEIGA ${ }^{3}$, J. A. SILVA Jr. ${ }^{2}$, P. J. F. TUCCI ${ }^{3}$
}

${ }^{1}$ Universidade Federal da Paraíba, João Pessoa, Paraíba, Brazil, ${ }^{2}$ Universidade Nove de Julho, São Paulo, SP, Brazil, ${ }^{3}$ Universidade Federal de São Paulo, São Paulo, SP, Brazil, ${ }^{4}$ Universidade Federal do Espírito Santo, Vitória, Espírito Santo, Brazil, ${ }^{5}$ Universidade São Judas Tadeu, São Paulo, SP, Brazil, ${ }^{6}$ Max-Delbrück-Center for Molecular Medicine (MDC), Berlin-Buch, Germany, ${ }^{7}$ Johns Hopkins University School of Medicine, Baltimore, USA

Received January 9, 2017

Accepted June 2, 2017

On-line September 22, 2017

\begin{abstract}
Summary
Our aim was to evaluate whether endothelial overexpressing of the bradykinin B1 receptor could be associated with altered left ventricular and myocardial performance. Echocardiography and hemodynamic were employed to assess left ventricular morphology and function in Sprague Dawley transgenic rats overexpressing the endothelial bradykinin B1 receptor (Tie2B1 rats). The myocardial inotropism was evaluated on papillary muscles contracting in vitro. In Tie2B1 animals, an enlarged left ventricular cavity and lower fractional shortening coupled with a lower rate of pressure change values indicated depressed left ventricular performance. Papillary muscle mechanics revealed that both Tie2B1 and wild-type rat groups had the same contractile capacities under basal conditions; however, in transgenic animals, there was accentuated inotropism due to post-pause potentiation. Following treatment with the $\mathrm{Arg}^{9}$-BK agonist, Tie2B1 papillary muscles displayed a reduction in myocardial inotropism. Endothelial B1 receptor overexpression has expanded the LV cavity and worsened its function. There was an exacerbated response of papillary muscle in vitro to a prolonged resting pause, and the use of a B1 receptor agonist impairs myocardial inotropism.
\end{abstract}

\section{Key words}

Bradykinin receptor - Cardiac structure - Cardiac function • Myocardial function • Transgenic rat

\section{Corresponding author}

P. J. F. Tucci, Rua Estado de Israel 181 - apt 94 - Postal code 04022-000, São Paulo, SP, Brazil. E-mail: paulotucci@ terra.com.br

\section{Introduction}

The kallikrein-kininogen system modulates various physiological processes and exerts protective and/or inductive actions in pathological conditions. These actions occur through endogenous kinins, such as bradykinin (BK), kallidin and Met-Lys-bradykinin, which are generated by the action of plasma and tissue-type kallikreins on hepatic kininogens (Wu et al. 2002, Calixto et al. 2004, Marceau and Regoli 2004). The synthesis, degradation and action of the kinins evoke well-documented effects, including modulation of the vascular tonus (Levesque et al. 1995), inflammation (Campos et al. 1998), nociception and pain (Calixto et al. 2004). In addition, kinins are implicated in pathological states such as asthma, allergies, rheumatoid arthritis, cystitis, gastritis, sepsis, pancreatitis, and cancer (Campos et al. 1998, McLean et al. 2000).

The kinin actions are mediated by two G proteinlinked receptors: $\mathrm{B}_{1}$ receptor $(\mathrm{B} 1 \mathrm{R})$ and $\mathrm{B}_{2}$ receptor (McLean et al. 2000, Oztürk 2001). The $\mathrm{B}_{2}$ receptor is constitutively expressed in mammals and shows high 
affinity for $\mathrm{BK}$ and low affinity for des-Arg 9 -BK (DABK) and Lys-des-Arg ${ }^{9}$-BK metabolites (Pesquero et al. 2000, Regoli 2000). The B1R is absent or lowly expressed in physiological situations, but may be functional under different pathological conditions (Pesquero et al. 2000, Prado et al. 2002). Currently available information does not fully clarify the physiological role of the B1R. As the kallikrein-kininogen system is present in the heart (Lagneux et al. 2002), the cardiac physiological relevance of the B1R needs to be determined. Genetically modified rodents are useful models for investigating the series of events initiated by specific membrane receptors. The work conducted on mice deficient in B1R showed that BR1-null mice develop less systolic tension in isolated heart preparations and reduced intracellular $\mathrm{Ca}^{2+}$ transients in whole-cell voltage clamp mode (Lauton-Santos et al. 2007). Rats that constitutively overexpress the B1R in the endothelium (Tie2B1) were bred to enable the direct investigation of the action of the $\mathrm{B} 1 \mathrm{R}$ on heart physiology. There is evidence that the B1R could interfere with cardiac homeostasis. It has been shown that the B1R exert key effects on the heart (Xu et al. 2013), and in the absence of the $B_{2}$ receptor, $B 1 R$ and angiotensin 2 receptors play an important role in preventing the deterioration of cardiac function post-infarction. However, we are unaware of any studies that examined the hypothesis that the overexpression of $\mathrm{B} 1 \mathrm{R}$ in the endothelium may alter heart structure and function.

\section{Methods}

\section{Animals and ethics}

Male transgenic Sprague Dawley rats (aged 10 weeks) overexpressing the B1R (Tie2B1) exclusively in the endothelium (Merino et al. 2008) and wild-type controls (C) were acquired from the Centre for the Development of Experimental Models of the Federal University of São Paulo. This study was approved by the Research Ethics Committee of the Federal University of São Paulo (protocol number: 1990/09) and conducted according to "Laws Referring to Animal Testing in Brazil" (http://www.ccs.ufpb.br/pesqces/animal.htm) and Guide for the Care and Use of Laboratory Animals (1985).

\section{Echocardiographic study}

Rats were anesthetized with a mixture of $50 \mathrm{mg} / \mathrm{kg}$ ketamine and $10 \mathrm{mg} / \mathrm{kg}$ xylazine and placed in a left lateral decubitus position to obtain echocardiographic images. Analyses of the left ventricle (LV) were conducted using SONOS $5500^{\circledR}$ equipment (Hewlett Packard, Andover, MA, USA) as previously described (Antonio et al. 2015, Sofia et al. 2014). Images in cross-sectional cuts were recorded on video tape for later evaluation. In the left parasternal view (longitudinal and cross-sectional) and apical view (four chambers and two chambers), the following variables were obtained in M mode: LV diastolic (LVDd) and end-systolic (LV ESd) diameters. The LV systolic function was determined by the fractional shortening (FS): FS (\%) = LVDd - LVESd/LVDd x 100.

The pulsatile Doppler technique was applied for the analyses of the diastolic function of the LV considering the diastolic flow velocity curve obtained from the apical four chamber cut: E wave, the highest value of the initial flow velocity of the LV filling; A wave, the highest value of the telediastolic mitral flow velocity; and ratio E/A, the ratio between $\mathrm{E}$ wave and $\mathrm{A}$ wave.

\section{LV hemodynamics}

Immediately after the echocardiography, the animals were kept warm $\left( \pm 37^{\circ} \mathrm{C}\right)$ in spontaneous respiration of air enriched with oxygen (0.6-0.8 1/min). A Millar micromanometer (MikroTip ${ }^{\circledR} 2 \mathrm{~F}$, Millar Instruments Inc., Houston, TX, USA) was inserted inside the LV cavity from the right carotid artery catheterization. After a right thoracotomy, a flow sensor (Transonic Systems Inc., NY, USA) coupled to the signal amplification system (Flow Meter - T206, Transonic Systems Inc., NY, USA) was positioned in the ascending aorta. The following data were obtained using AcqKnowledge ${ }^{\circledR}$ 3.7.5. software (Biopac Systems Inc., CA, USA): heart rate (HR, bpm), LV systolic (LVSP, $\mathrm{mm} \mathrm{Hg}$ ) and end-diastolic (LVEDP, $\mathrm{mm} \mathrm{Hg}$ ) pressures, maximum positive $(+\mathrm{dP} / \mathrm{dt}, \mathrm{mm} \mathrm{Hg} / \mathrm{s})$ and negative $(-\mathrm{dP} / \mathrm{dt}, \mathrm{mm} \mathrm{Hg} / \mathrm{s})$ rates of intraventricular pressure, cardiac output (CO, $\mathrm{ml} / \mathrm{min})$, ejected systolic volume (ESV, ml) and stroke work (SW, gm/beat). SW was calculated by the equation: $\mathrm{SW}=($ LVSP - LVEDP $\mathrm{x}$ ESV) $x$ constant 0.0136 . The values of $\mathrm{LV}$ ejection were indexed according to body mass: $\mathrm{CO}$ index (COI), SV index (SVI) and stroke work index (SWI).

\section{Myocardial performance in vitro}

After hemodynamic study, the animals received a urethane overdose $(4.8 \mathrm{~g} / \mathrm{kg}$ i.p. $)$, the hearts were quickly removed and LV posterior papillary muscles were removed as previously described (Reis Junior et al. 
2016). The papillary muscle was dissected; stainless steel rings were connected to its ends and it was dipped vertically into a glass cube filled with $5 \mathrm{ml}$ KrebsHenseleit solution (mmol: $135 \mathrm{NaCl}, 4.6 \mathrm{KCl}, 1.5 \mathrm{CaCl}$, $1.15 \mathrm{MgSO}_{4}, 1.2 \mathrm{KH}_{2} \mathrm{PO}_{4}, 5.5$ glucose and 20 HEPES, $\mathrm{pH} 7.45$ and $100 \% \mathrm{O}_{2}$ ). The lower end of the muscle was fixed to the cube and the upper portion was connected to the force transducer (GRASS FT-03, Astro-Med Inc., RI, USA). The force transducer was coupled to a micromanipulator (No. 2046F, Mitutoyo Inc., Kawasaki, Japan), which allows vertical displacements of $10 \mu \mathrm{m}$ per turn. All the muscles were stimulated at a frequency of $0.2 \mathrm{~Hz}$. For $60 \mathrm{~min}$, the tissues were kept in isotonic contraction with low pre-load (3 mg). Next, the muscles were manipulated to develop isometric contraction, and then the myocardium was stretched until it reached the apex of the length/tension curve (diastolic length at which the developed isometric tension reached maximum value, $\mathrm{L}_{\max }$ ). Different variables were used to analyze myocardial performance under basal conditions: maximum developed tension (DT), rest tension (RT), and maximum positive $(+\mathrm{dT} / \mathrm{dt})$ and negative $(-\mathrm{dT} / \mathrm{dt})$ rates of tension variation. DT- and RT-dependent values of muscle lengths were registered, corresponding to $92 \%$, $94 \%, 96 \%, 98 \%$ of the $\mathrm{L}_{\max }$ (Serra et al. 2010) defining length/tension relations (Frank-Starling mechanism). Moreover, post-pause potentiation was evaluated by interrupting muscle stimulation for intervals of 10,15 , 30,45 and $60 \mathrm{~s}$ and estimating post-pause potentiation from the ratio between the first beat following the pause and the last beat before the interval (Bocalini et al. 2012). In addition, contractile response to the B1R agonist was evaluated. Increasing doses $\left(10^{-12}\right.$ to $\left.10^{-4} \mathrm{M}\right)$ of DABK (1006276; Bachem Americas-Torrance, CA, USA) were added to Krebs-Henseleit solution and DT was recorded continuously. Once the maneuvers for assessing myocardial function were completed, the muscles were weighed. The cross-section area of the muscle was estimated (muscle weight/length at rest in $\mathrm{L}_{\max }$ ) considering a muscle density equal to 1 . All data were corrected for the cross-sectional area of the muscle.

\section{Statistical analysis}

Data were analyzed with the Prism 4.0 program (GraphPad Prism Software Inc., San Diego, CA, USA). Student's t-test and two-way ANOVA with post hoc Bonferroni test were applied on the comparisons. The results are showed as the means \pm standard error of mean, and the level of significance was set at $p \leq 0.05$.

\section{Results}

\section{Overexpression of the B1R alters LV geometry}

There were no significant differences in body weight between the Tie2B1 and C groups (Table 1). Similar results were observed for the heart, right ventricle and LV weights. Echocardiographic findings revealed that Tie2B1 rats did not exhibit alterations in LV wall thickness. However, the geometry of the cavity was substantially altered. Indeed, the overexpression of the $\mathrm{B} 1 \mathrm{R}$ induced an increase in LV diastolic and systolic diameters.

\section{$B 1 R$ overexpression and ventricular performance}

Echocardiographic analyses of the LV (Table 1) revealed a significant reduction of the $\mathrm{FS}$ in the Tie2B1 group compared to the $C$ group $(p=0.02)$. No alterations were identified in the Tie2B1 group for different indicators of $\mathrm{LV}$ diastolic function ( $\mathrm{E}$ and $\mathrm{A}$ waves and the E/A ratio) obtained by the Doppler method. Hemodynamic data (Table 2) showed that Tie2B1 and $C$ rats exhibited similar values for HR, LVSP, LVEDP and $\mathrm{CO}$. Interestingly, the increased B1R expression was associated with significant reduction of the $+\mathrm{dP} / \mathrm{dt}$ $(\mathrm{p}=0.0006)$ and $-\mathrm{dP} / \mathrm{dt}(\mathrm{p}=0.03)$, indicating a reduction in LV performance. Despite these findings, we did not identify any alteration in different indicators of the ejection function of the LV (Table 2). Indeed, data referring to $\mathrm{CO}, \mathrm{SV}, \mathrm{SW}, \mathrm{COI}, \mathrm{SVI}$ and $\mathrm{SWI}$ were similar for the two groups.

\section{$B 1 R$ overexpression and myocardial performance}

The results of the preparations of the isometrically contracting papillary muscles at $\mathrm{L}_{\max }$ are displayed in Table 3. Notably, in the basal condition, the inotropism indicators (DT and $+\mathrm{dT} / \mathrm{dt}$ ) and myocardial relaxation $(-\mathrm{dT} / \mathrm{dt})$ were not significantly altered in the Tie2B1 animals compared to the $\mathrm{C}$ group. Muscle rest tension (RT) was the only significantly altered variable, as it was reduced in the Tie2B1 animals.

The DT analysis of different muscle lengths was performed relying on the linear function: $y=a+b x$, where $x$ represents the slope of the line. The lowest correlation coefficient verified between the points was $r=0.9899$. The slopes of the lines of regression for DT were $0.25 \pm 0.1$ for Tie2B1 animals and $0.26 \pm 0.07$ for $\mathrm{C}$ animals ( $\mathrm{p}>0.05)$ (Fig. 1A). These findings indicate that the overexpression of the B1R in the endothelium does not modify the myocardial sensitivity to stretching. 
Table 1. Influence of B1R overexpression on LV morphology and Doppler echocardiographic data.

\begin{tabular}{lccc}
\hline Variable & $\mathbf{C}$ & Tie2B1 & \\
& $(\mathbf{n}=\mathbf{1 0})$ & $\mathbf{( n = 1 4 )}$ & p-value \\
\hline Body weight $(\mathrm{g})$ & $355 \pm 16$ & $375 \pm 11$ & 0.1 \\
Heart rate $(\mathrm{bpm})$ & $250 \pm 22$ & $248 \pm 22$ & 0.5 \\
Heart weight $(\mathrm{mg})$ & $972 \pm 51$ & $1126 \pm 156$ & 0.1 \\
RV weight $(\mathrm{mg})$ & $225 \pm 27$ & $283 \pm 61$ & 0.5 \\
LV weight $(\mathrm{mg})$ & $747 \pm 45$ & $842 \pm 101$ & 0.4 \\
Echocardiography & & & \\
AWTd $(\mathrm{mm})$ & $0.16 \pm 0.005$ & $0.17 \pm 0.004$ & 0.5 \\
AWTs $(\mathrm{mm})$ & $0.27 \pm 0.01$ & $0.26 \pm 0.008$ & 0.2 \\
PWTd $(\mathrm{mm})$ & $0.17 \pm 0.06$ & $0.22 \pm 0.06$ & 0.9 \\
PWTs $(\mathrm{mm})$ & $0.26 \pm 0.01$ & $0.25 \pm 0.08$ & 0.3 \\
Diastolic diameter $(\mathrm{cm})$ & $0.78 \pm 0.02$ & $0.86 \pm 0.02 *$ & 0.03 \\
Systolic diameter $(\mathrm{cm})$ & $0.45 \pm 0.02$ & $0.54 \pm 0.02^{*}$ & 0.02 \\
FS $(\%)$ & $42 \pm 2$ & $35 \pm 1 *$ & 0.9 \\
E wave $(\mathrm{cm} / \mathrm{s})$ & $86 \pm 4$ & $86 \pm 2$ & 0.2 \\
A wave $(\mathrm{cm} / \mathrm{s})$ & $38 \pm 4$ & $33 \pm 2$ & 0.2 \\
E/A ratio & $2.4 \pm 0.2$ & $2.7 \pm 0.2$ & \\
\hline
\end{tabular}

RV, right ventricle; LV, left ventricle; AWTd, anterior wall thickness in diastole; AWTs, anterior wall thickness in systole; PWTd, posterior wall thickness in diastole; PWTs, posterior wall thickness in systole; FS, fractional shortening; $E$ wave, the highest value of the initial flow velocity for ventricular filling; A wave, the highest value of the mitral telediastolic flow velocity; E/A ratio, the ratio between the maximum velocity of the $\mathrm{E}$ wave and the maximum velocity of the $\mathrm{A}$ wave. $*$ Significantly difference of the $\mathrm{C}$ group.

Overexpression of the BIR and post-pause potentiation

As illustrated in Figure 1B, the post-pause potentiation was substantially enhanced by overexpression of the $\mathrm{B} 1 \mathrm{R}$. Indeed, the relative contractions (ratio between the DT of the first post-pause beat and the basal beat) of Tie2B1 animals was increased compared to $\mathrm{C}$ animals. The areas below the curves demonstrate the simplistic analysis of the post-pause contraction and the pause time of the stimulus (Fig. 1C). The transgenic animals had area under the curve values that were significantly increased compared to the $\mathrm{C}$ animals, indicating a greater sensitivity of the Tie2B1 rats to the post-pause contraction.

Overexpression of the $B 1 R$ and contractile response to the $D A B K$

The papillary muscles at $\mathrm{L}_{\max }$ were exposed to increasing doses of DABK $\left(10^{-12}\right.$ to $\left.10^{-4} \mathrm{M}\right)$, and the contractile response was continuously recorded. The plotting of dose-response curves revealed that the transgenic animals showed a negative inotropic response at a concentration of $10^{-10} \mathrm{M}$ DABK and higher (Fig. 1B). The wild-type animals did not present DT alterations regardless of DABK dose.

\section{Discussion}

This study details geometry and LV performance as well as the mechanical performance of the myocardium in rats overexpressing the $\mathrm{B} 1 \mathrm{R}$ in the endothelium (Merino et al. 2008). To our knowledge, there are no previous studies conducted within this scope.

A few studies have shown that B1R activation induces cardiovascular effects. An increase in arterial pressure after intravenous administration of DABK was shown in transgenic mice constitutively overexpressing B1R using a cytomegalovirus immediate-early gene enhancer/promoter (Ni et al. 2003). Furthermore, we found only one additional study that assessed the role of the B1R in cardiac function. Using Langendorff preparations of B1R-null mice, less developed tension and an increase in coronary perfusion pressure were described, and these findings were associated with a reduction in the $\mathrm{Ca}^{2+}$ transient in the cardiomyocyte (Lauton-Santos et al. 2007). 
Table 2. Left ventricle hemodynamic data of $\mathrm{C}$ and Tie2B1 animals.

\begin{tabular}{|c|c|c|c|}
\hline Variable & $\begin{array}{c}C \\
(n=6)\end{array}$ & $\begin{array}{c}\text { Tie2B1 } \\
(n=8)\end{array}$ & p-value \\
\hline$H R(b p m)$ & $246 \pm 32$ & $213 \pm 16$ & 0.1 \\
\hline LVSP (mm Hg) & $132 \pm 5$ & $122 \pm 5$ & 0.09 \\
\hline LVEDP (mm Hg) & $4 \pm 2$ & $3 \pm 1$ & 0.2 \\
\hline$+d P / d t(m m ~ H g / s)$ & $8934 \pm 653$ & $6470 \pm 241^{*}$ & 0.0006 \\
\hline$-d P / d t(m m ~ H g / s)$ & $-6080 \pm 693$ & $-4866 \pm 177^{*}$ & 0.03 \\
\hline $\mathrm{CO}(\mathrm{ml} / \mathrm{min})$ & $59 \pm 5$ & $56 \pm 13$ & 0.4 \\
\hline$S V(m l)$ & $0.19 \pm 0.02$ & $0.2 \pm 0.06$ & 0.4 \\
\hline$C I\left(m l . \mathrm{min}^{-1} \cdot \mathrm{kg}^{-1}\right)$ & $174 \pm 22$ & $153 \pm 33$ & 0.3 \\
\hline$S V I\left(m l . \mathrm{kg}^{-1}\right)$ & $0.57 \pm 0.08$ & $0.55 \pm 0.13$ & 0.4 \\
\hline$S W I\left(g \cdot m \cdot b a t^{-1} \cdot \mathrm{kg}^{-1}\right)$ & $1.06 \pm 0.13$ & $0.89 \pm 0.19$ & 0.2 \\
\hline
\end{tabular}

$\mathrm{HR}$, heart rate; LVSP, LV systolic pressure; LVEDP, LV end diastolic pressure; $+\mathrm{dP} / \mathrm{dt}$, maximum positive rate of intraventricular pressure; $-\mathrm{dP} / \mathrm{dt}$, maximum negative rate of intraventricular pressure; $\mathrm{CO}$, cardiac output; SV, stroke volume. $\mathrm{CI}$, cardiac index; SVI, stroke volume index; SWI, stroke work index. * Significantly difference of the C group.

Table 3. Myocardial performance of isolated papillary muscles under basal conditions.

\begin{tabular}{lccc}
\hline Variable & $\begin{array}{c}\mathbf{C} \\
(\mathbf{n = 9 )}\end{array}$ & $\begin{array}{c}\text { Tie2B1 } \\
(\mathbf{n}=\mathbf{1 0})\end{array}$ & $\begin{array}{c}\text { p-value } \\
\end{array}$ \\
\hline$C S A\left(\mathrm{~mm}^{2}\right)$ & $1.02 \pm 0.11$ & $0.93 \pm 0.06$ & 0.5 \\
$D T\left(\mathrm{~g} / \mathrm{mm}^{2}\right)$ & $5.2 \pm 0.34$ & $5.2 \pm 0.51$ & 0.9 \\
$+d T / d t\left(\mathrm{~g} / \mathrm{mm}^{2} / \mathrm{s}\right)$ & $49 \pm 4$ & $49 \pm 6$ & 0.9 \\
$-d T / d t\left(\mathrm{~g} / \mathrm{mm}^{2} / \mathrm{s}\right)$ & $-19 \pm 3$ & $-24 \pm 3$ & 0.2 \\
$R T\left(\mathrm{~g} / \mathrm{mm}^{2}\right)$ & $0.97 \pm 0.1$ & $0.62 \pm 0.09 *$ & 0.02 \\
\hline
\end{tabular}

CSA, cross-sectional area of the muscles; DT, developed tension; $+d T / d$, maximum positive rate of developed tension; $-\mathrm{dT} / \mathrm{dt}$, maximum negative rate of developed tension; RT, resting tension. * Significantly difference of the C group.
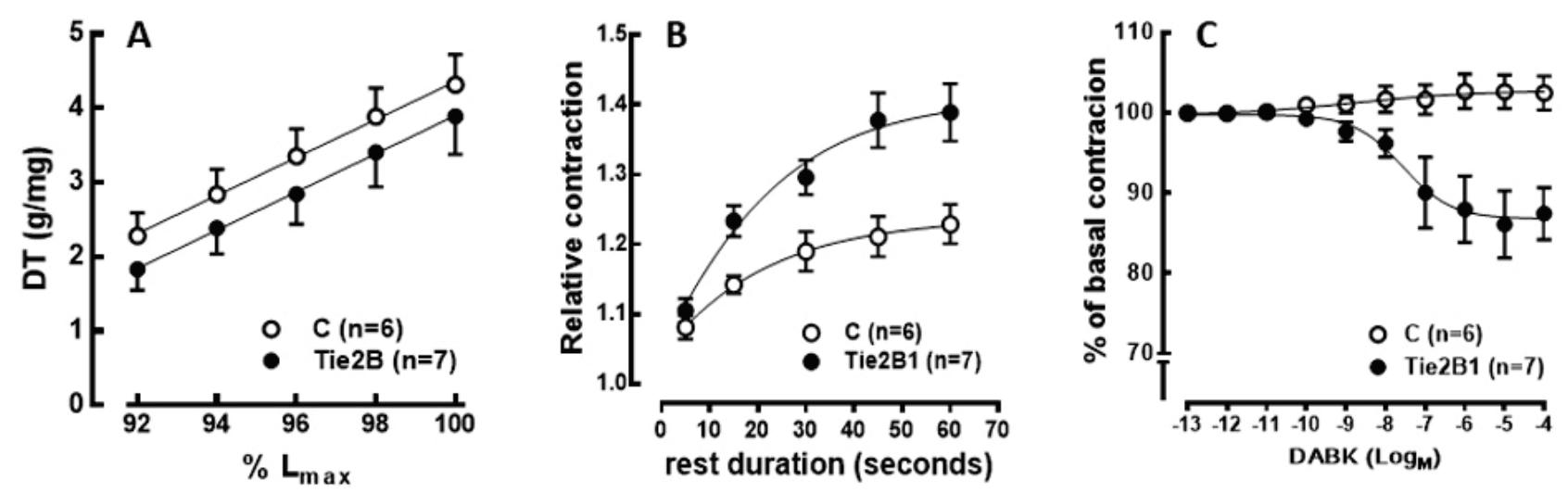

Fig. 1. A. Straight lines were fitted to the developed length $\left(\% L_{\max }\right)-$ tension relationships. The mean slopes of the regression lines were compared between C and Tie2B1 groups. B. Contractile muscle response to Arg ${ }^{9}-\mathrm{BK}$ (DABK) agonist. C. Post-rest contraction (PRC) of isolated papillary muscle preparations. The PRC was derived as a relationship for steady-state contraction. The relative contraction from the Tie2B1 group was shifted upwards in relation to the $C$ group. $* p<0.05$ vs. C group. 
In our study, Tie2B1 rats showed significant FS reduction and $\mathrm{B} 1 \mathrm{R}$ overexpression resulted in lower values for $+\mathrm{dP} / \mathrm{dt}$. These findings suggest that, in these rats, LV performance in situ is depressed by an increase in the expression of the B1R in the endothelium.

It seems that $\mathrm{B} 1$ and $\mathrm{B} 2$ can promote vasodilation in conductance and resistance vessels, which is mediated essentially by NO (Bélichard et al. 1996, Erdos et al. 2010). Supposedly, these peripheral actions could affect cardiac function. Notwithstanding, our data in hemodynamics does not indicate differences in respect to: LV systolic pressure, LV end diastolic pressure, cardiac output, stroke volume, cardiac index, stroke volume index, stroke work index. Only first derivatives of pressure (positive and negative) denote differences between wild and transgenic rats. These results allow us to consider that there were no expressive differences in respect to systemic vascular function and peripheral vascular resistance among the control and Tie2B1 animals. In connection with this fact, we have no data on receptors (B1, B2, angiotensin receptors) interactions and this question remains to be determined.

The basal results derived from the isolated papillary muscles contradict the hypothesis that LV performance of Tie2B1 would result from depressed myocardial inotropism in intact animals. Indeed, in the isolated, buffer-nourished myocardium, the capacity to generate tension under basal conditions was similar between Tie2B1 and $\mathrm{C}$ animals (Table 3), indicating a similarity in basal myocardial inotropism between the two groups. This similarity was also noted in the study of stretching/DT relations. Frank-Starling relations did not reveal differences in myocardial sensitivity to stretching between Tie2B1 and $\mathrm{C}$ animals (Fig. 1A). Another interesting finding in this study corresponds to the reduced RT in Tie2B1 animals. There are no data in the literature that enables the justification of this difference.

Papillary muscles subjected to different intervals of electrical stimulation and post-pause analyses of myocardial mechanics resulted in data that differ between $\mathrm{C}$ and Tie2B1 animals. This maneuver enables the determination of the scavenging action of calcium into the sarcoplasmic reticulum (SR) by the action of SERCA 2 in opposition to the contrary effect of the $\mathrm{Na}^{+} / \mathrm{Ca}^{2+}$ exchanger, which tends to exclude $\mathrm{Ca}^{2+}$ from the cytosol during pause (Bers 2008). In a normal rat myocardium, a longer pause promotes a greater accumulation and liberation of $\mathrm{Ca}^{2+}$ from the SR (Shattock and Bers 1989, Bers 2008) due to the bypassing of SERCA 2 action with respect to the $\mathrm{Na}^{+} / \mathrm{Ca}^{2+}$ exchanger. Interestingly, the constitutive overexpression of the B1R evoked a stronger tension in response to a longer stimulus interval in Tie2B1 rats (Fig. 1B), characterizing an accentuated predominance of inflow over outflow of $\mathrm{Ca}^{2+}$ in Tie2B1. In studies conducted in knockout mice, the absence of the B1R resulted in reduced $\mathrm{Ca}^{2+}$ transient in isolated cardiomyocytes (Lauton-Santos et al. 2007). It seems logical that, reciprocally, an overexpression of the B1R causes an opposite response to that observed in knockout rodents. Therefore, under the stimulus of a longer pause, the intracellular kinetics of the $\mathrm{Ca}^{2+}$ could be favored in the myocardium of Tie2B1 rats, conditioning the accentuation of the post-pause contraction despite the myocardial contractile capacity under basal conditions being comparable to that in the $\mathrm{C}$ animals.

Considering that overexpression of the B1R resulted in an accentuation of the contractile capacity after a longer stimulation interval, it was anticipated that the action of DABK should exacerbate the DT. In contrast, after receptor stimulation, overexpression of the B1R proved to be detrimental to myocardial inotropism. There is no evidence in our data, or in the literature, that offers an explanation for this puzzling question. Notwithstanding, it is possible that post-pause and DABK can promote opposite effects on the excitation-contraction coupling, supporting that direct activation of endothelial B1R causes weakened contractions by a paracrine effect. Furthermore, if B1R prevails under systemic influence in situ heart of overexpressed animals, our finding of reduced ventricular performance in $\mathrm{B} 1 \mathrm{R}$ with respect to $\mathrm{C}$ suggests systemic inotropic depression in the overexpressed animals even though isolated nourished papillary mechanics of the two groups showed similar inotropism in the absence of B1R stimulation.

In conclusion, in situ hearts of rats overexpressing the B1R exclusively in the endothelium have expanded LV cavities with reduced capacity to generate pressure and shortening, suggesting myocardial depression. Experiments conducted to assess isolated buffer-nourished myocardial function indicated the normality of the basal inotropism, with an exacerbated response to a prolonged resting pause. Nevertheless, our data indicated that the use of a specific B1R agonist impairs inotropism, suggesting that systemic conditions activated the BR1R in situ hearts of Tie2B1 animals, lowering myocardial contractility. 


\section{Conflict of Interest}

There is no conflict of interest.

\section{Acknowledgements}

We thank the Fundação de Amparo à Pesquisa do Estado de São Paulo (FAPESP) (Grant numbers 09/54225-8 and 2015/11028-9) and Conselho Nacional de Desenvolvimento Científico e Tecnológico (CNPq) (Grant numbers 47840/2011-5 and 479395/2012-8) for funding this study.

\section{References}

ANTONIO EL, SERRA AJ, DOS SANTOS AA, VIEIRA SS, SILVA JM, YOSHIZAKI A, SOFIA RR, TUCCI PJ: Are there gender differences in left ventricular remodeling after myocardial infarction in rats? Rev Bras Cir Cardiovasc 30: 70-76, 2015.

BÉLICHARD P, LOILLIER B, PAQUET JL, LUCCARINI JM, PRUNEAU D: Haemodynamic and cardiac effects of kinin B1 and B2 receptor stimulation in conscious instrumented dogs. Br J Pharmacol 117: 1565-1571, 1996.

BERS DM: Calcium cycling and signaling in cardiac myocytes. Annu Rev Physiol 70: 23-49, 2008.

BOCALINI DS, DOS SANTOS L, ANTONIO EL, SANTOS AA, DAVEL AP, ROSSONI LV, VASSALO DV, TUCCI PJ: Myocardial remodeling after large infarcts in rat converts post rest-potentiation in force decay. Arq Bras Cardiol 98: 243-251, 2012.

CALIXTO JB, MEDEIROS R, FERNANDES ES, FERREIRA J, CABRINI DA, CAMPOS MM: Kinin B1 receptors: key G-protein-coupled receptors and their role in inflammatory and painful processes. Br J Pharmacol 143: 803-818, 2004.

CAMPOS MM, SOUZA GE, CALIXTO JB: Modulation of kinin B1 but not B2 receptors-mediated rat paw edema by IL-1 $\beta$ and TNF $\alpha$. Peptides 19: 1269-1276, 1998.

ERDÖS EG, TAN F, SKIDGEL RA: Angiotensin I-converting enzyme inhibitors are allosteric enhancers of kinin B1 and B2 receptor function. Hypertension 55: 214-220, 2010.

LAGNEUX C, BADER M, PESQUERO JB, DEMENGE P, RIBUOT C: Detrimental implication of B1 receptors in myocardial ischemia: evidence from pharmacological blockade and gene knockout mice. Int Immunopharmacol 2: 815-822, 2002.

LAUTON-SANTOS S, GUATIMOSIM S, CASTRO CH, OLIVEIRA FA, ALMEIDA AP, DIAS-PEIXOTO MF, GOMES MA, PESSOA P, PESQUERO JL, PESQUERO JB, BADER M, CRUZ JS: Kinin B1 receptor participates in the control of cardiac function in mice. Life Sci 81: 814-822, 2007.

LEVESQUE L, HARVEY N, RIOUX F, DRAPEAU G, MARCEAU F: Development of a binding assay for the B1 receptors for kinins. Immunopharmacology 29: 141-147, 1995.

MARCEAU F, REGOLI D: Bradykinin receptor ligands: therapeutic perspectives. Nat Rev Drug Discov 3: 845-852, 2004.

MCLEAN PG, PERRETTI M, AHLUWALIA A: Kinin B(1) receptors and the cardiovascular system: regulation of expression and function. Cardiovasc Res 48: 194-210, 2000.

MERINO VF, TODIRAS M, CAMPOS LA, SAUL V, POPOVA E, BALTATU OC, PESQUERO JB, BADER M: Increased susceptibility to endotoxic shock in transgenic rats with endothelial overexpression of kinin $\mathrm{B}(1)$ receptors. J Mol Med 86: 791-798, 2008.

NI A, YIN H, AGATA J, YANG Z, CHAO L, CHAO J: Overexpression of kinin B1 receptors induces hypertensive response to des-Arg9-bradykinin and susceptibility to inflammation. J Biol Chem 278: 219-225, 2003.

OZTÜRK Y: Kinin receptors and their antagonists as novel therapeutic agents. Curr Pharm Des 7: 135-161, 2001.

PESQUERO JB, ARAUJO RC, HEPPENSTALL PA, STUCKY CL, SILVA JA JR, WALTHER T, OLIVEIRA SM, PESQUERO JL, PAIVAO AC, CALIXTO JB, LEWIN GR, BADER M: Hypoalgesia and altered inflammatory responses in mice lacking kinin B1 receptors. Proc Natl Acad Sci USA 97: 8140-8145, 2000.

PRADO GN, TAYLOR L, ZHOU X, RICUPERO D, MIERKE DF, POLGAR P: Mechanisms regulating the expression, self-maintenance, and signaling-unction of the bradykinin B2 and B1 receptors. J Cell Physiol 193: 275-286, 2002.

REGOLI D: Toward a new anti-inflammatory and analgesic agent. Proc Natl Acad Sci USA 97: 7676-7677, 2000. 
REIS JUNIOR D, ANTONIO EL, DE FRANCO MF, DE OLIVEIRA HA, TUCCI PJ, SERRA AJ: Association of exercise training with tobacco smoking prevents fibrosis but has adverse impact on myocardial mechanics. Nicotine Tob Res 18: 2268-2272, 2016.

SERRA AJ, SANTOS MH, BOCALINI DS, ANTONIO EL, LEVY RF, SANTOS AA, HOGUCHI ML, SILVA JA, MAGALHÃES FC, BARAUNA VG, KRIEGER JE, TUCCI PJ: Exercise training inhibits inflammatory cytokines and more than prevents myocardial dysfunction in rats with sustained beta-adrenergic hyperactivity. J Physiol 588: 2431-2442, 2010.

SHATTOCK MJ, BERS DM: Rat vs. rabbit ventricle: Ca flux and intracelular $\mathrm{Na}$ assessed by ion-selective microelectrodes. Am J Physiol 256: C813-C822, 1989.

SOFIA RR, SERRA AJ, SILVA JA JR, ANTONIO EL, MANCHINI MT, OLIVEIRA FA, TEIXEIRA VP, TUCCI PJ: Gender-based differences in cardiac remodeling and ILK expression after myocardial infarction. Arq Bras Cardiol 103: 124-130, 2014.

WU D, LIN X, BERNLOEHR C, HILDEBRANDT T, DOODS H: Effects of a novel bradykinin B1 receptor antagonist and angiotensin II receptor blockade on experimental myocardial infarction in rats. PloS One 7: e51151, 2002.

XU J, CARRETERO OA, ZHU L, SHESELY EG, RHALEB NE, DAI X, WANG L, YANG JJ, YANG XP: Protective role of $\mathrm{AT}(2)$ and $\mathrm{B}(1)$ receptors in kinin $\mathrm{B}(2)$-receptor-knockout mice with myocardial infarction. Clin Sci 124: 87-96, 2013. 